\begin{tabular}{c|c|c}
\hline ISSN 2525-4812 (versão online) & Revista Terceira \\
$\begin{array}{c}\text { ISSN 2238-7641 (versão impressa) } \\
\text { http://www.revistaterceiramargem.com/ } \\
\text { index.php/terceiramargem/index }\end{array}$ & $\begin{array}{c}\text { Recebido em: 19/6/2019 } \\
\text { Aprovado em: } 30 / 2 / 2020\end{array}$ & $\begin{array}{c}\text { Revisaço } \\
\text { Margem Amazônia }\end{array}$ \\
\hline
\end{tabular}

Como citar o artigo:

SILVA, T. M. R; TAVARES, J. M. F. Lei 13.123/2015, a proteção do conhecimento tradicional e o controle de convencionalidade. Revista Terceira Margem Amazônia, v. 6, n.15, p. 17-43, 2020. Doi: http://dx.doi.org/10.36882/25254812.2020v6i15p17-43.

\title{
A LEI 13.123/2015, A PROTEÇÃO DO CONHECIMENTO TRADICIONAL E O CONTROLE DE CONVENCIONALIDADE
}

\author{
Túlio Macedo Rosa e Silva ${ }^{1}$ \\ Jaíse Marien Fraxe Tavares ${ }^{2}$
}

Resumo: Esta pesquisa teve como objetivo estudar a compatibilidade da Lei 13.123/15, em especial seus artigos $2^{\circ}$, inciso III e $9^{\circ}$, com a Convenção 169 da Organização Internacional do Trabalho e com a Convenção da Diversidade Biológica. Com isso, buscou-se expor as normas jurídicas internacionais de proteção das comunidades tradicionais e do conhecimento tradicional associado, bem como analisar a natureza jurídica dos tratados internacionais no ordenamento jurídico interno e a sua relação com o controle de convencionalidade. Concluiu-se que no que se refere à consulta prévia, livre e informada, a Lei 13.123/2015 é incompatível com a Convenção sobre Diversidade Biológica e a Convenção $\mathrm{n}^{\circ} 169$ da OIT. A metodologia utilizada nesta pesquisa quanto aos meios foi desenvolvida por meio do método dedutivo, descritivo e qualitativo, através da análise doutrinária, bibliográfica e jurisprudencial. Quanto aos fins, a pesquisa foi qualitativa.

Palavras-chave: Controle de Convencionalidade. Convenção 169 da Organização Internacional do Trabalho. Convenção sobre Diversidade Biológica. Conhecimento Tradicional Associado.

\begin{abstract}
This research is aimed to study the compatibility of Law 13.123/15, especially its Articles 2, III and 9, with Convention 169 of the International Labor Organization and the Convention on Biological Diversity. The purpose of this study was to present international legal norms for the protection of traditional communities and associated traditional knowledge, as well as to analyze the legal nature of international treaties in the domestic juridical order and their relation to conventionality control. The conclusion is

\footnotetext{
${ }^{1}$ Possui graduação em Direito pela Universidade de São Paulo (2008). Mestrado em Direito e Processo do Trabalho pela Universidade de São Paulo (2012). Doutorado em Direito e Processo do Trabalho pela Universidade de São Paulo (2018). É Juiz do Trabalho do Tribunal Regional do Trabalho da $11^{\text {a }}$ Região e professor Adjunto da Universidade do Estado do Amazonas.

${ }^{2}$ Mestre em Direito Ambiental pela Universidade do Estado do Amazonas (2020), Especialista em Direito Público pela Universidade do Estado do Amazonas (2019) e Graduada em Direito pela Universidade do Estado do Amazonas (2017). Advogada e professora.
} 
Law 13.123/2015 is incompatible with the Convention on Biological Diversity and Convention 169of the International Labor Organization. The methodology used in this research regarding the means was developed through the deductive, descriptive and qualitative method, through the doctrinal, bibliographical and jurisprudential analysis. As for the purposes, the research was qualitative.

Keywords: Conventionality Control. Convention 169 of the International Labor Organization. Convention on Biological Diversity. Associated Traditional Knowledge.

\section{INTRODUÇÃO}

Este trabalho possui como objetivo estudar a compatibilidade da Lei 13.123/15, em especial seus artigos $2^{\circ}$, inciso III e $9^{\circ}$, com a Convenção 169 da Organização Internacional do Trabalho e com a Convenção da Diversidade Biológica.

Com isso, busca-se expor as normas jurídicas internacionais de proteção das comunidades tradicionais e do conhecimento tradicional associado, bem como analisar a natureza jurídica dos tratados internacionais no ordenamento jurídico interno e a sua relação com o controle de convencionalidade.

A Convenção $n^{\circ}$ 169/OIT de 1989 internalizada no ordenamento jurídico brasileiro em 2002, aplicável a povos indígenas e comunidades tradicionais, rompeu com o paradigma integracionista e buscou trazer maior proteção à diversidade cultural, determinando, em seu art. $6^{\circ} .1$ a a realização do instituto da consulta prévia aos povos interessados cada vez que sejam previstas medidas legislativas ou administrativas suscetíveis de afetá-los diretamente:

\footnotetext{
Ao aplicar as disposições da presente Convenção, os governos deverão consultar os povos interessados, mediante procedimentos apropriados e, particularmente, através de suas instituições representativas, cada vez que sejam previstas medidas legislativas ou administrativas suscetíveis de afetá-los diretamente; (grifo nosso).
}

Nesta mesma linha, a Convenção sobre Diversidade Biológica, ratificada no Brasil pelo Decreto Federal n 2.519 de 16 de março de 1998, determina, em seu art. $8^{\text {o }}$, “j”, que o Estado deve:

Em conformidade com sua legislação nacional, respeitar, preservar e manter o conhecimento, inovações e práticas das comunidades locais e populações indígenas com estilo de vida tradicionais relevantes à conservação e à utilização sustentável da diversidade biológica e incentivar sua mais ampla aplicação com a aprovação e a participação dos detentores desse conhecimento, inovações e práticas; e encorajar a repartição equitativa dos benefícios oriundos da utilização desse conhecimento, inovações e práticas. (Grifo nosso) 
Além disso, a Convenção sobre Diversidade Biológica determina, em seu art. 15, que "o acesso aos recursos genéticos deve estar sujeito ao consentimento prévio fundamentado_da Parte Contratante provedora desses recursos, a menos que de outra forma determinado por essa Parte". (grifo nosso).

A Constituição Federal de 1988 revela a preocupação do Constituinte em preordenar e inovar com normas que pudessem efetivamente proteger os direitos e interesses dos povos indígenas e comunidades tradicionais.

Conforme o conceito trazido pelo art. $3^{\circ}$, I, do Decreto 6.040, de 7 de fevereiro de 2007, comunidades tradicionais são:

Art. $3^{\circ}$. Para os fins deste Decreto e do seu Anexo compreende-se por:

I - Povos e Comunidades Tradicionais: grupos culturalmente diferenciados e que se reconhecem como tais, que possuem formas próprias de organização social, que ocupam e usam territórios e recursos naturais como condição para sua reprodução cultural, social, religiosa, ancestral e econômica, utilizando conhecimentos, inovações e práticas gerados e transmitidos pela tradição.

Neste mesmo sentido, temos o conceito de população tradicional estampado no art. 3을 II da Lei 11.428/2006, como aquela população que vive em "estreita relação com o ambiente natural, dependendo de seus recursos naturais para a sua reprodução sociocultural, por meio de atividades de baixo impacto ambiental".

A Lei $13.123 / 2015^{1}$, objeto de análise do presente trabalho, trouxe o conceito de conhecimento tradicional associado em seu art. $2^{\circ}$, incisos II e III, criando uma subcategoria, qual seja, a de "conhecimento tradicional associado" e "conhecimento tradicional de origem não identificável".

Neste sentido, o art. $2^{\circ}$, II da Lei 13.123/2015 conceitua conhecimento tradicional associado como "informação ou prática de população indígena, comunidade tradicional ou agricultor tradicional sobre as propriedades ou usos diretos ou indiretos associada ao patrimônio genético".

Já o inciso III do art. $2^{\circ}$ da Lei 13.123/2015 cria uma nova categoria não prevista na Convenção 169 da OIT, nem na Convenção sobre Diversidade Biológica, o "conhecimento tradicional associado de origem não identificável", conceituando-o como o "conhecimento tradicional associado em que não há a possibilidade de vincular a sua

\footnotetext{
${ }^{1}$ Regulamenta o inciso II do $\S 10$ e o $\S 4$ o do art. 225 da Constituição Federal, o Artigo 1, a alínea j do Artigo 8, a alínea c do Artigo 10, o Artigo 15 e os §§ 3o e 4o do Artigo 16 da Convenção sobre Diversidade Biológica, promulgada pelo Decreto no 2.519, de 16 de março de 1998; dispõe sobre o acesso ao patrimônio genético, sobre a proteção e o acesso ao conhecimento tradicional associado e sobre a repartição de benefícios para conservação e uso sustentável da biodiversidade; revoga a Medida Provisória no 2.186-16, de 23 de agosto de 2001; e dá outras providências.
} 
origem a, pelo menos, uma população indígena, comunidade tradicional ou agricultor tradicional".

Outrossim, a Lei 13.123/2015 dita que o consentimento prévio informado é obrigatório apenas na hipótese de acesso ao conhecimento tradicional associado de origem identificável, conforme dispõe o seu artigo $9^{\circ}$.

Deste modo, haverá isenção do consentimento prévio informado na hipótese de acesso ao conhecimento tradicional associado não identificável, nos termos do art. $9^{\circ}, \S$ $2^{\circ}$ da Lei $13.123 / 2015$.

Ademais, no próprio processo de elaboração da Lei 13.123/2015 não houve consulta prévia a povos indígenas e comunidades tradicionais, conforme determinam a Convenção 169 da OIT e a Convenção sobre a Diversidade Biológica.

Desta forma, o questionamento trazido neste trabalho é: a Lei 13.123/2015 é compatível com as normas internacionais que tratam do conhecimento tradicional associado, em especial a Convenção sobre Diversidade Biológica e a Convenção 169 da Organização Internacional do Trabalho?

O problema abordado nesta pesquisa justifica-se tendo em vista que o Brasil é detentor de imensurável sociobiodiversidade, principalmente nos paradigmas étnico e cultural, o que tornou o patrimônio ambiental material e imaterial alvo de inúmeras ações de apropriação indevida, desde o período de colonização do país.

Deste modo, faz-se necessário analisar a natureza jurídica dos tratados internacionais de proteção da biodiversidade no sistema jurídico brasileiro como parâmetro para o controle de convencionalidade da Lei 13.123/2015, de modo a estudar as categorias de povos e comunidades tradicionais, relacionando-as com suas normas de proteção.

Além do estudo de matéria afeta aos direitos de povos indígenas e comunidades tradicionais, cuida-se simultaneamente, sobretudo, de temática inserida no âmbito dos direitos econômicos, sociais, culturais e ambientais, demonstrando o caráter indivisível, interdependente e complementar dos Direitos Humanos.

A metodologia utilizada nesta pesquisa quanto aos meios foi desenvolvida por meio do método dedutivo e descritivo, tendo em vista que esses métodos possibilitam levar o investigador a conclusões baseadas em análise de premissas tidas como verdadeiras com uma margem pequena de erro.

Do ponto de vista dos procedimentos técnicos adotados a pesquisa foi realizada por meio da análise doutrinária, bibliográfica, baseando-se em conteúdos e dados 
extraídos de livros, artigos, pesquisas realizadas sobre o tema, de estudos que mostrem, comprovem e forneçam informações válidas nos alcances dos objetivos da pesquisa e, principalmente, dos textos de tratados internacionais que buscam proteger a biodiversidade e o conhecimento tradicional associado.

A forma de abordagem do problema foi desenvolvida por meio da pesquisa qualitativa, uma vez que não se vão medir dados, mas sim identificar suas naturezas.

\section{A POSIÇÃo HIERÁRQUICA DOS TRATAdOS INTERNACIONAIS SOBRE DIREITOS HUMANOS NO DIREITO BRASILEIRO}

O estudo acerca da posição hierárquica dos tratados internacionais sobre direitos humanos é indispensável na hipótese de um conflito entre o Direito Internacional dos Direitos Humanos e o Direito Interno, como ocorre no objeto de estudo do presente trabalho.

Neste caso, suscita-se a seguinte indagação: como solucionar eventual conflito entre a legislação interna e determinados tratados internacionais de proteção dos direitos humanos? Qual norma deve prevalecer?

Esta discussão acerca da natureza jurídica dos tratados internacionais sobre direitos humanos no ordenamento jurídico brasileiro já existia com o $\$ 2^{\circ 2}$ do art. $5^{\circ}$ da Constituição Federal, inserido pelo poder constituinte originário e aumentou mais ainda com o acréscimo do $\S 3^{\circ}$ através da Emenda Constitucional n ${ }^{\circ} 45$ de 2004, que determinou:

Art. $5^{\circ}, \S 3^{\circ}$ : Os tratados e convenções internacionais sobre direitos humanos que forem aprovados, em cada Casa do Congresso Nacional, em dois turnos, por três quintos dos votos dos respectivos membros, serão equivalentes às emendas constitucionais.

Com a inserção do $\S 3^{\circ}$ no texto constitucional, foi aberta margem ao Poder Legislativo para uma dupla possibilidade no que tange ao rito de aprovação dos tratados internacionais sobre direitos humanos: a de decreto legislativo em paridade a uma lei ordinária ou a de decreto legislativo em equivalência a uma emenda constitucional (LOUREIRO e BRITO SILVA, 2009, p. 192).

Ou seja, de um lado, vigora a cláusula aberta constante, originariamente, no $\S 2^{\circ}$ do artigo $5^{\circ}$ que confere aos tratados internacionais de direitos humanos ratificados pelo

\footnotetext{
${ }^{2} \S 2^{\circ}$ Os direitos e garantias expressos nesta Constituição não excluem outros decorrentes do regime e dos princípios por ela adotados, ou dos tratados internacionais em que a República Federativa do Brasil seja parte.
} 
Brasil status de norma materialmente constitucional e; de outro lado, o novo $\$ 3^{\circ}$ do mesmo artigo $5^{\circ}$, que atribui aos tratados internacionais status equivalente à emenda constitucional somente se aprovados pelo Congresso Nacional com o rito de dois turnos de discussão e votação com quórum qualificado de três quintos para sua aprovação em cada Casa (LOUREIRO e BRITO SILVA, 2009, p. 192).

Nesta esteira, conforme Loureiro (2007, p. 17), “o legislador ordinário, investido de mero poder reformador, molda o texto constitucional à interpretação assentada pelas teses majoritárias da Corte Suprema, desvirtuando completamente o sentido e o alcance da cláusula final do $\S 2^{\circ}$, ainda vigente".

Sobre o assunto, Feliciano (2009, p. 124) também se posiciona no sentido de que há dois regimes concomitantes desde a inserção do $\S 3^{\circ}$ do art. $5^{\circ}$ da Constituição Federal, mas, em tese distinta, diferencia a posição hierárquica no ordenamento jurídico brasileiro nos casos em que tratado internacional refere-se à norma-princípio ou à norma-regra.

Segundo Feliciano (2009, p. 124), normas principiológicas são imediatamente incorporadas ao rol de garantias e direitos individuais, por força do $\S 2^{\circ}$ do art. $5^{\circ}$ da Constituição Federal:

O primeiro regime dá-se por derivação principiológica imediata, lastreado na norma do art. $5^{\circ}, \S 2^{\circ}$. Por ele, princípios imanentes a tratados ou convenções internacionais são imediatamente incorporados ao rol de direitos e garantias individuais, tornando-se desde logo cognoscíveis e sindicáveis judicialmente. Insista-se, porém, que - pela própria letra constitucional (“[...] não excluem outros decorrentes do regime e dos princípios por ela adotados, ou dos tratados internacionais em que a República Federativa do Brasil seja parte") —, tal regime de recepção só serve aos princípios (i.e., às normas dotadas de conteúdo imediatamente axiológico, máxima abstração e caráter normogenético); não serve às regras que, mediante comandos mais concretos, densificam aqueles princípios. (i.e., às normas dotadas de conteúdo imediatamente axiológico, máxima abstração e caráter normogenético); não serve às regras que, mediante comandos mais concretos, densificam aqueles princípios.

Nesta linha, Feliciano (2009, p. 124) defende que nos casos de norma-regra, ou seja, comandos concretos, que densificam os princípios, estes só possuem natureza jurídica constitucional após o processo legislativo equivalente ao das emendas constitucionais:

O segundo regime dá-se por derivação vinculada a ato de legitimação congressual (com quórum de emenda constitucional), lastreado, hoje, na norma do art. $5^{\circ}, \S 3^{\circ}$. Nesse caso, o texto normativo internacional incorpora-se por inteiro, em nível constitucional, mas não antes do devido processo legislativo, que equivale aos das emendas (aprovação, em cada Casa do Congresso Nacional, em dois turnos, por três quintos dos votos dos respectivos membros).

O posicionamento mais recente do Supremo Tribunal Federal sobre a matéria ocorreu no julgamento da possibilidade de prisão civil do depositário infiel (RE. 
349.703/RS. Rel. Min. Carlos Britto. Rel. Acordão Min. Gilmar Mendes. Tribunal Pleno, julgamento em 03/12/08, DJe-104 de 05/06/09), cuja matéria de fundo era a compatibilidade do art. $7^{\circ}(7)^{3}$ da Convenção Americana de Direitos Humanos e do art. $5^{\circ}$, LXVII ${ }^{4}$ da Constituição Federal:

PRISÃO CIVIL DO DEPOSITÁRIO INFIEL EM FACE DOS TRATADOS INTERNACIONAIS DE DIREITOS HUMANOS. INTERPRETAÇÃO DA PARTE FINAL DO INCISO LXVII DO ART. 5O DA CONSTITUIÇÃO BRASILEIRA DE 1988. POSIÇÃO HIERÁRQUICO-NORMATIVA DOS TRATADOS INTERNACIONAIS DE DIREITOS HUMANOS NO ORDENAMENTO JURÍDICO BRASILEIRO. Desde a adesão do Brasil, sem qualquer reserva, ao Pacto Internacional dos Direitos Civis e Políticos (art. 11) e à Convenção Americana sobre Direitos Humanos - Pacto de San José da Costa Rica (art. $\left.7^{\circ}, 7\right)$, ambos no ano de 1992, não há mais base legal para prisão civil do depositário infiel, pois o caráter especial desses diplomas internacionais sobre direitos humanos lhes reserva lugar específico no ordenamento jurídico, estando abaixo da Constituição, porém acima da legislação interna. O status normativo supralegal dos tratados internacionais de direitos humanos subscritos pelo Brasil torna inaplicável a legislação infraconstitucional com ele conflitante, seja ela anterior ou posterior ao ato de adesão. Assim ocorreu com o art. 1.287 do Código Civil de 1916 e com o Decreto-Lei n ${ }^{\circ}$ 911/69, assim como em relação ao art. 652 do Novo Código Civil (Lei ${ }^{\circ}$ 10.406/2002). ALIENAÇÃ̃O FIDUCIÁRIA EM GARANTIA. DECRETOLEI N ${ }^{\circ}$ 911/69. EQUIPAÇÃO DO DEVEDOR-FIDUCIANTE AO DEPOSITÁRIO. PRISÃO CIVIL DO DEVEDOR-FIDUCIANTE EM FACE DO PRINCÍPIO DA PROPORCIONALIDADE. A prisão civil do devedor-fiduciante no âmbito do contrato de alienação fiduciária em garantia viola o princípio da proporcionalidade, visto que: a) o ordenamento jurídico prevê outros meios processuais-executórios postos à disposição do credor-fiduciário para a garantia do crédito, de forma que a prisão civil, como medida extrema de coerção do devedor inadimplente, não passa no exame da proporcionalidade como proibição de excesso, em sua tríplice configuração: adequação, necessidade e proporcionalidade em sentido estrito; e b) o Decreto-Lei $\mathrm{n}^{\circ}$ 911/69, ao instituir uma ficção jurídica, equiparando o devedor-fiduciante ao depositário, para todos os efeitos previstos nas leis civis e penais, criou uma figura atípica de depósito, transbordando os limites do conteúdo semântico da expressão "depositário infiel" insculpida no art. $5^{\circ}$, inciso LXVII, da Constituição e, dessa forma, desfigurando o instituto do depósito em sua conformação constitucional, o que perfaz a violação ao princípio da reserva legal proporcional. RECURSO EXTRAORDINÁRIO CONHECIDO E NÃO PROVIDO (grifo nosso).

Este julgamento registrou divergência de entendimento entre os ministros do Supremo Tribunal Federal sobre duas teses, a de que os tratados de direitos humanos devem ingressar no ordenamento jurídico como normas constitucionais e a tese outra,

\footnotetext{
${ }^{3}$ Ninguém deve ser detido por dívidas. Este princípio não limita os mandados de autoridade judiciária competente expedidos em virtude de inadimplemento de obrigação alimentar.

${ }^{4}$ LXVII - não haverá prisão civil por dívida, salvo a do responsável pelo inadimplemento voluntário e inescusável de obrigação alimentícia e a do depositário infiel.
} 
vencedora, no sentido de que os tratados que versam sobre direitos humanos não devem ser incorporados como normas constitucionais, mas como normas que têm natureza supralegal: abaixo da Constituição, mas acima das leis.

Ou seja, embora não seja unânime, prevalece nesta Corte Suprema que apenas os tratados de direitos humanos aprovados com o quorum qualificado do $\S 3^{\circ}$, do art. $5^{\circ}$, da Constituição Federal, possuem status constitucional. Assim, os demais tratados de direitos humanos, aprovados sem este rito, possuem natureza supralegal.

Sobre o tema, Cançado Trindade, em análise feita em voto em separado, no julgamento do Caso Damião Ximene Lopes vs Brasil, posicionou-se no sentido de criticar a outorga de status constitucional apenas aos tratados de direitos humanos aprovados por maioria de 3/5 dos membros de cada Casa do Congresso Nacional, afirmando se tratar de um verdadeiro retrocesso:

\begin{abstract}
Esta nova disposição busca outorgar, de forma bisonha, status constitucional, no âmbito do direito interno brasileiro, tão só aos tratados de direitos humanos que sejam aprovados por maioria de $3 / 5$ dos membros tanto da Câmara dos Deputados como do Senado Federal (passando assim a ser equivalentes a emendas constitucionais). Mal concebido, mal redigido e mal formulado, representa um lamentável retrocesso em relação ao modelo aberto consagrado pelo parágrafo 2 do artigo 5 da Constituição Federal de 1988, que resultou de uma proposta de minha autoria à Assembleia Nacional Constituinte, como historicamente documentado. (Corte Interamericana de Direitos Humanos. Caso Damião Ximenes Lopez vs. Brasil, sentença de 4 de julho de 2006, parágrafos 30 e 31 do citado voto em separado).
\end{abstract}

Acerca da posição hierárquica dos tratados internacionais em patamar inferior ao da Constituição, Mazzuoli (2005, p. 235), aponta que, se a própria Constituição estabelece que os direitos e garantias nela elencados podem ser complementados por outros provenientes de tratados ( $\$ 2^{\mathrm{a}}$ do art. $5^{\mathrm{o}}$ da Constituição Federal), não se poderia concluir que esses outros direitos e garantias tivessem um grau hierárquico diferente das normas constitucionais em vigor.

Neste sentido, Mazzuoli (2000, p. 32):

Ora, se a Constituição estabelece que os direitos e garantias nela elencados 'não excluem' outros provenientes dos tratados internacionais em que a República Federativa do Brasil seja parte (art. $5^{\circ}, \S 2^{\circ}$ ) é porque ela própria está a autorizar que esses direitos e garantias internacionais constantes dos tratados internacionais ratificados pelo Brasil 'se incluem' no nosso ordenamento jurídico interno, passando a ser considerados como se escritos na Constituição estivessem. É dizer, se os direitos e garantias expressos no texto constitucional 'não excluem' outros provenientes dos tratados internacionais em que o Brasil seja parte é porque, pela lógica, na medida em 
que tais instrumentos passam a assegurar certos direitos e garantias, a Constituição 'os inclui' no seu catálogo de direitos protegidos, ampliando, assim, o seu 'bloco de constitucionalidade'.(grifo nosso).

Deste modo, segundo Mazzuoli (2000, p. 32), fazem parte do bloco de constitucionalidade todos aqueles tratados internacionais de direitos humanos dos quais o Brasil é signatário, por força do $\S 2^{\circ}$ do art. $5^{\circ}$.

Sobre o bloco de constitucionalidade, ensina Canotilho (2003, p. 921):

O programa normativo-constitucional não se pode reduzir, de forma positivística, ao "texto" da constituição. Há que densificar, em profundidade, as normas e princípios da constituição, alargando o "bloco de constitucionalidade" a princípios não escritos desde que reconduzíveis ao programa normativo constitucional como formas de densificação ou revelação específicas de princípios ou regras constitucionais positivamente plasmadas.

Nesta esteira, destaca Piovesan (2000, p. 97) que a Constituição de 1988 inovou ao incluir, dentre os direitos constitucionalmente protegidos, os direitos enunciados nos tratados internacionais de direitos humanos de que o Brasil seja signatário $\left(\$ 2^{\circ}\right.$ do art. $5^{\circ}$ da Constituição Federal) e, ao efetuar tal incorporação, a Constituição atribuiu aos direitos internacionais uma natureza especial e diferenciada, qual seja, a natureza de norma constitucional.

No ordenamento jurídico brasileiro a hierarquia constitucional das normas internacionais sobre direitos humanos dos quais o Brasil é signatário justifica-se principalmente porque, tomando como base o texto constitucional originário (parte final do $\S 2^{\circ}$ do art. $5^{\circ}$ ), não há que se falar em procedimento mais gravoso para a inclusão no catálogo de direitos e garantias fundamentais dos tratados internacionais sobre direitos humanos (LOUREIRO e SILVA BRITO, 2009, p. 200).

Ademais, conforme Loureiro e Silva Brito (2009, p.200), nem mesmo o artigo 60 da Constituição que trata do processo legislativo de emendas previu a necessidade da equivalência do rito adotado no seu parágrafo $2^{\circ}$ para incorporação de tratados internacionais sobre direitos humanos.

Por conseguinte, na hipótese de eventual conflito entre o Direito Internacional dos Direitos Humanos e o Direito Interno, deve-se adotar o critério da norma mais favorável à vítima, consoante a lição de Cançado Trindade (1991, p. 3-4): "No domínio da proteção dos direitos humanos, interagem o direito internacional e o direito interno 
movidos pelas mesmas necessidades de proteção, prevalecendo as normas que melhor protejam o ser humano. A primazia é da pessoa humana".

Este trabalho defende que os direitos e garantias expressos na Carta Magna não excluem outros decorrentes do regime e dos princípios por ela adotados, ou dos tratados internacionais sobre direitos humanos em que a República Federativa do Brasil seja parte, ou seja, tendo eles natureza constitucional, independentemente do rito previsto no art. $5^{\circ}$, $\S 3^{\circ}$ da Constituição Federal.

Assim, os tratados internacionais sobre direitos humanos formam juntamente com as demais disposições escritas na Constituição, o bloco de constitucionalidade, servindo como parâmetro para análise da compatibilidade das normas jurídicas do direito interno, conforme será analisado no tópico a seguir.

Aliás, ainda que se entenda que as normas internacionais sobre direitos humanos não tenham natureza jurídica de norma constitucional sem a aprovação conforme o rito previsto no $\S 3^{\circ}$ do art. $5^{\circ}$ da Constituição Federal, conforme o entendimento atual do Supremo Tribunal Federal, os tratados internacionais sobre direitos humanos possuem patamar hierárquico acima das leis (natureza jurídica de "supralegalidade"), razão pela qual ainda mais se justifica a necessidade da compatibilidade das leis brasileiras com a Convenção 169 da OIT e com a Convenção da Diversidade Biológica, objeto de estudo do presente trabalho.

\section{PROTEÇÃO JURÍDICA DAS COMUNIDADES TRADICIONAIS NO BRASIL}

Para a análise da compatibilidade da Lei 13.125/2015 com o Direito Internacional, é imprescindível o estudo acerca do conjunto normativo que protege as comunidades tradicionais no Brasil.

O direito internacional e os sistemas jurídicos nacionais têm desenvolvido um conjunto de direitos dos povos indígenas e comunidades tradicionais destinado, de um lado, a reparar, em parte, as exclusões históricas e, de outro, a proporcionar condições para um novo paradigma entre os estados, os povos indígenas e a sociedade (FAJARDO, 2009, p. 13).

Moreira (2006, p. 309-332) enumera os principais instrumentos normativos internacionais relacionados às questões afetas ao conhecimento tradicional associado, quais sejam: a Convenção da Diversidade Biológica (CDB), o Acordo TRIPS no âmbito 
da Organização Mundial do Comércio (OMC), o Tratado de Recursos Fitogenéticos da FAO, a Convenção sobre Patrimônio Imaterial da UNESCO e a Convenção 169 da OIT.

Para fins de análise da convencionalidade da Lei 13.123/2015, faz-se necessário realizar o recorte epistemológico nos tratados internacionais que tratam sobre a consulta prévia, livre e informada, especificamente, a Convenção no 169 da Organização Internacional do Trabalho (OIT) e a Convenção sobre Diversidade Biológica (CDB).

A Convenção $n^{\circ}$ 169/OIT de 1989, internalizada no ordenamento jurídico brasileiro pelo Decreto $n^{\circ} 5.051$, de 19 de abril de 2004, rompeu com a concepção integracionista anteriormente veiculada pela Convenção $n^{\circ}$ 107/OIT que, conforme Fajardo (2009, p. 20), “alienava os povos indígenas da capacidade de tomar decisões sobre o seu destino".

Deste modo, a Convenção 169 da OIT ofereceu diretrizes mínimas para que os Estados nacionais respeitem a diversidade de formas de expressão e da organização social dos povos indígenas e tribais, por meio do diálogo e da consulta.

Neste sentido, ensina Fajardo (2009, p.15) que "o Convênio 169, rompe explicitamente com o integracionismo e estabelece as bases de um modelo pluralista, baseado no controle indígena de suas próprias instituições e modelo de desenvolvimento, e na sua participação nas políticas estatais".

Interessante destacar que a Convenção $n^{\circ} 169$ da OIT é aplicada não apenas à concepção de povos indígenas, como também aos povos tidos como tribais ${ }^{5}$ e, assim, às comunidades tradicionais.

Neste sentido, temos como exemplo os seguintes julgados dos tribunais constitucionais da América Latina: Sentencia del Tribunal Constitucional del Perú. Expte. $n^{\circ}$ 0022-2009-PI/TC, par.36; Corte de Constitucionalidad de Guatemala, 21 de diciembre de 2009, Apelación de sentencia de Amparo, Expte. 3878-2007, V.a; Corte Constitucional de Bolivia, Sentencia Constitucional 2003/2010-E, de 25 de ouctubre de 2010, Expte. 2008-17547-36-RAC. III-5.

A Convenção 169 da OIT prevê, em seu artigo $6^{\circ 6}$, a obrigatoriedade dos Estados

\footnotetext{
${ }^{5}$ Povos que possuem condições sociais, culturais e econômicas que os distinguem de outros setores da coletividade nacional, e que estão regidos, total ou parcialmente, por seus próprios costumes ou tradições ou por legislação especial.

${ }^{6}$ Artigo $6^{\circ}$ 1. Ao aplicar as disposições da presente Convenção, os governos deverão: a) consultar os povos interessados, mediante procedimentos apropriados e, particularmente, através de suas instituições representativas, cada vez que sejam previstas medidas legislativas ou administrativas suscetíveis de afetálos diretamente.
} 
de consultar os povos indígenas e comunidades tradicionais interessados diante de medidas administrativas ou legislativas capazes de afetá-los diretamente mediante procedimentos apropriados, inclusive por meio de suas instituições representativas (ARAÚJO JÚNIOR, 2018, p. 24-25).

Nesta esteira, a Convenção da Diversidade Biológica, fruto da Conferência das Nações Unidas sobre Meio Ambiente e Desenvolvimento, a Eco-92, realizada no Rio de Janeiro, ratificada pelo Brasil por meio do Decreto Legislativo ${ }^{\circ} 2$ de 1994, estabelece, em seu art. $8^{\circ}, \mathrm{j}$, o dever dos Estados de:

j) Em conformidade com sua legislação nacional, respeitar, preservar e manter o conhecimento, inovações e práticas das comunidades locais e populações indígenas com estilo de vida tradicionais relevantes à conservação e à utilização sustentável da diversidade biológica, e incentivar sua mais ampla aplicação com a aprovação e a participação dos detentores desse conhecimento inovações e práticas; e encorajar a repartição equitativa dos benefícios oriundos da utilização desse conhecimento, inovações e práticas.

Com isso, a determinação da Convenção sobre a Diversidade Biológica é a de que o conhecimento, as inovações e as práticas das comunidades tradicionais e povos indígenas devem ser respeitadas, sendo fundamental a aprovação e participação dos detentores deste conhecimento para a sua aplicação e utilização.

A Convenção sobre a Diversidade Biológica reconheceu a estreita e tradicional dependência de recursos biológicos de muitas comunidades locais e populações indígenas, com estilo de vida tradicionais, sendo obrigatória a repartição equitativa dos benefícios derivados da utilização do conhecimento tradicional, de inovações e de práticas relevantes à conservação da diversidade biológica e à utilização sustentável de seus componentes (SILVA, 2002, p. 130-131).

Deste modo, os direitos de propriedade intelectual não podem se opor à proteção da diversidade biológica, nem à utilização sustentável de seus componentes e a repartição justa e equitativa dos benefícios derivados da utilização dos recursos genéticos, conforme os objetivos expostos na Convenção sobre Diversidade Biológica e o disposto no art. 16.5. ${ }^{7}$ da referida Convenção (MIRANDA, 2015, p. 84).

\footnotetext{
${ }^{7}$ Artigo 16 Acesso à Tecnologia e Transferência de Tecnologia [...] 5. As Partes Contratantes, reconhecendo que patentes e outros direitos de propriedade intelectual podem influir na implementação desta Convenção, devem cooperar a esse respeito em conformidade com a legislação nacional e o direito internacional para garantir que esses direitos apoiem e não se oponham aos objetivos desta Convenção.
} 


\author{
Além disso, a Convenção da Diversidade Biológica faz menção expressa ao \\ consentimento prévio para acesso aos recursos genéticos, in verbis:
}

\begin{abstract}
Artigo 15 Acesso a recursos genéticos [...] 5. O acesso aos recursos genéticos deve estar sujeito ao consentimento prévio fundamentado da Parte Contratante provedora desses recursos, a menos que de outra forma determinado por essa Parte. [...] (grifo nosso)
\end{abstract}

No âmbito do direito interno brasileiro, a Constituição Federal de 1988 deu um largo passo à frente na questão indígena, comunidades quilombolas e povos tradicionais, com vários dispositivos tratando da matéria, dentre os quais se destacam os artigos 215 , caput e parágrafo primeiro ${ }^{8}, 216^{9}$ e 231 e parágrafos ${ }^{10}$ que dispõem sobre a propriedade

\footnotetext{
${ }^{8}$ Art. 215. O Estado garantirá a todos o pleno exercício dos direitos culturais e acesso às fontes da cultura nacional, e apoiará e incentivará a valorização e a difusão das manifestações culturais.

$\S 1^{\circ} \mathrm{O}$ Estado protegerá as manifestações das culturas populares, indígenas e afro-brasileiras, e das de outros grupos participantes do processo civilizatório nacional.

9 Art. 216. Constituem patrimônio cultural brasileiro os bens de natureza material e imaterial, tomados individualmente ou em conjunto, portadores de referência à identidade, à ação, à memória dos diferentes grupos formadores da sociedade brasileira, nos quais se incluem:

I - as formas de expressão;

II - os modos de criar, fazer e viver;

III - as criações científicas, artísticas e tecnológicas;

IV - as obras, objetos, documentos, edificações e demais espaços destinados às manifestações artísticoculturais;

$\mathrm{V}$ - os conjuntos urbanos e sítios de valor histórico, paisagístico, artístico, arqueológico, paleontológico, ecológico e científico.

${ }^{10}$ Art. 231. São reconhecidos aos índios sua organização social, costumes, línguas, crenças e tradições, e os direitos originários sobre as terras que tradicionalmente ocupam, competindo à União demarcá-las, proteger e fazer respeitar todos os seus bens.

$\S 1^{\circ}$ São terras tradicionalmente ocupadas pelos índios as por eles habitadas em caráter permanente, as utilizadas para suas atividades produtivas, as imprescindíveis à preservação dos recursos ambientais necessários a seu bem-estar e as necessárias a sua reprodução física e cultural, segundo seus usos, costumes e tradições.

$\S 2^{\circ}$ As terras tradicionalmente ocupadas pelos índios destinam-se a sua posse permanente, cabendo-lhes o usufruto exclusivo das riquezas do solo, dos rios e dos lagos nelas existentes.

$\S 3^{\circ} \mathrm{O}$ aproveitamento dos recursos hídricos, incluídos os potenciais energéticos, a pesquisa e a lavra das riquezas minerais em terras indígenas só podem ser efetivados com autorização do Congresso Nacional, ouvidas as comunidades afetadas, ficando-lhes assegurada participação nos resultados da lavra, na forma da lei.

$\S 4^{\circ}$ As terras de que trata este artigo são inalienáveis e indisponíveis, e os direitos sobre elas, imprescritíveis.

$\S 5^{\circ}$ É vedada a remoção dos grupos indígenas de suas terras, salvo, "ad referendum" do Congresso Nacional, em caso de catástrofe ou epidemia que ponha em risco sua população, ou no interesse da soberania do País, após deliberação do Congresso Nacional, garantido, em qualquer hipótese, o retorno imediato logo que cesse o risco.

$\S 6^{\circ}$ São nulos e extintos, não produzindo efeitos jurídicos, os atos que tenham por objeto a ocupação, o domínio e a posse das terras a que se refere este artigo, ou a exploração das riquezas naturais do solo, dos rios e dos lagos nelas existentes, ressalvado relevante interesse público da União, segundo o que dispuser lei complementar, não gerando a nulidade e a extinção direito a indenização ou a ações contra a União, salvo, na forma da lei, quanto às benfeitorias derivadas da ocupação de boa fé.

$\S 7^{\circ}$ Não se aplica às terras indígenas o disposto no art. $174, \S 3^{\circ} \mathrm{e} \S 4^{\circ}$.
} 
de suas terras, a competência da União para legislar sobre povos indígenas, sobre as relações destas comunidades com suas terras, preservação de suas línguas, usos, costumes e tradições, de modo que estas normas pudessem efetivamente proteger os direitos e interesses dos índios e de comunidades tradicionais.

No que diz respeito à proteção do patrimônio genético, o inciso II, do $\S 1^{\circ}$, do art. $225^{11}$ da Constituição impôs ao poder público a obrigação de preservar a diversidade e a integridade do patrimônio genético do País, especialmente no que diz concerne à fiscalização das atividades de pesquisa e manipulação de material genético (OLIVEIRA, 2016, p. 78).

Apesar do texto constitucional não ter realizado referência expressa à proteção do conhecimento tradicional associado, Oliveira (2016, p. 78) destaca que "este se insere no mesmo campo de tutela na medida em que se concebe que o conhecimento tradicional associado é elemento intrínseco dos recursos genéticos".

Com estes dispositivos, a defesa da diversidade passa a ser inerente ao respeito à dignidade da pessoa humana no Brasil, conferindo direito dos grupos portadores de identidades específicas (povos indígenas e comunidades tradicionais) o controle de suas próprias instituições, formas de vida e desenvolvimento econômico, por meio do fortalecimento de suas entidades, línguas e religiões.

Nesta linha, disserta Duprat (2007, p. 10):

\begin{abstract}
A noção central, comum a esse conjunto de atos normativos, é de que, no seio da comunidade nacional, há grupos portadores de identidades específicas e que cabe ao direito assegurar-lhes o controle de suas próprias instituições e formas de vida e seu desenvolvimento econômico, e manter e fortalecer suas entidades, línguas e religiões, dentro do âmbito dos Estados onde moram. Assim, a defesa da diversidade cultural passa a ser, para os Estados nacionais, um imperativo ético, inseparável do respeito à dignidade da pessoa humana.
\end{abstract}

Por meio do novo paradigma constitucional de 1988, consoante Araújo Junior (2018, p. 4):

\footnotetext{
Não há inferioridade ou incapacidade civil, e sim grupos diferenciados que têm modos próprios de vida, os quais devem ser respeitados como tais" e, com isso, se consolida um histórico de lutas em todo o mundo - inclusive no Brasil - em favor da defesa de identidades e da igualdade como reconhecimento.
}

\footnotetext{
${ }^{11}$ Art. 225. Todos têm direito ao meio ambiente ecologicamente equilibrado, bem de uso comum do povo e essencial à sadia qualidade de vida, impondo-se ao Poder Público e à coletividade o dever de defendê-lo e preservá- lo para as presentes e futuras gerações.

$\S 1^{\circ}$ Para assegurar a efetividade desse direito, incumbe ao Poder Público:(omissis)

II - preservar a diversidade e a integridade do patrimônio genético do País e fiscalizar as entidades dedicadas à pesquisa e manipulação de material genético;
} 
Na legislação infraconstitucional brasileira, há previsão no art. $4^{\circ}$, inciso XIII da Lei 9.985/2000, como um dos objetivos do Sistema Nacional de Unidades de Conservação (SNUC): "XIII - proteger os recursos naturais necessários à subsistência de populações tradicionais, respeitando e valorizando seu conhecimento e sua cultura e promovendo-as social e economicamente" (grifo nosso).

Ainda na Lei 9.985/2000, temos previsão no art. 5, $\mathrm{X}$, como uma das diretrizes do SNUC, a garantia às populações tradicionais cuja subsistência dependa da utilização de recursos naturais existentes no interior das unidades de conservação meios de subsistência alternativos ou a justa indenização pelos recursos perdidos.

Este novo paradigma introduzido na Constituição Federal coloca os direitos dos povos tradicionais no campo dos direitos fundamentais, de modo a assegurar-lhes a dignidade da pessoa humana, conforme determina o art. $4^{\circ}$ da Declaração Universal sobre a Diversidade Cultural:

Artigo 4 - Os direitos humanos, garantias da diversidade cultural A defesa da diversidade cultural é um imperativo ético, inseparável do respeito à dignidade humana. Ela implica o compromisso de respeitar os direitos humanos e as liberdades fundamentais, em particular os direitos das pessoas que pertencem a minorias e os dos povos autóctones. Ninguém pode invocar a diversidade cultural para violar os direitos humanos garantidos pelo direito internacional, nem para limitar seu alcance.

Ao passo que as normas internacionais tutelam a biodiversidade e os conhecimentos tradicionais, reconhecendo a necessidade de consulta de povos e comunidades diretamente afetados, a Lei 13.123/2015 flexibilizou estes direitos e, até mesmo, permitiu a apropriação e utilização destes bens ambientais contra interesses socioambientais e difusos de países detentores de imensurável sociobiodiversidade, como o Brasil (MIRANDA, 2016, p. 80).

Com isso, passa-se à abordagem dos pontos em que a Lei 13.123/2015 é incompatível com o sistema jurídico brasileiro.

\section{A (IN)COMPATIBILIDADE DA LEI 13.123/2015 COM O SISTEMA JURÍDICO BRASILEIRO}

O exercício do controle de convencionalidade no Sistema Regional Americano de Proteção dos Direitos Humanos advém da construção jurisprudencial da 
Corte Interamericana de Direitos Humanos com o objetivo de proporcionar maior efetividade à proteção desse grupo de direitos.

Para consagração de sua proteção, é indispensável a busca pela efetividade dos diplomas que os declaram, quais sejam, os tratados internacionais, uma vez que a “comunicação entre as jurisdições nacionais e internacional certamente possibilita a construção de uma rede mais protetiva dos direitos humanos fundamentais" (SILVA, 2018, p. 119).

Neste sentido, ensina Bobbio (2004, p. 43) que "o problema fundamental em relação aos direitos do homem, hoje, não é tanto o de justificá-los, mas o de protegêlos", ou seja, vivemos a "era" da multiplicação e especialização dos direitos, onde, atualmente, os maiores desafios dos direitos humanos não são mais declará-los, mas sim, efetivá-los.

Deste modo, o controle de convencionalidade manifesta-se como um instrumento eficaz para o respeito, a garantia e a efetivação dos direitos descritos no Pacto de San José da Costa Rica (SAGÜES, 2010, p. 118) e nos demais tratados internacionais de direitos humanos.

De acordo com Ramos (2003, p. 86), é por meio deste controle que "as normas locais passam a ter a compatibilidade aferida diante das normas internacionais".

Com isso, o controle de convencionalidade é uma forma de traduzir a complementariedade dos sistemas de proteção de direitos humanos: o sistema jurídico internacional e o sistema interno de cada país, sendo o sistema interno aquele que possui a incumbência primária de proteção destes direitos e o sistema internacional aquele a quem cabe a atuação subsidiária (SILVA, 2018, p. 60).

Ademais, o controle de convencionalidade possui como fundamento a responsabilidade internacional dos Estados ao assumir obrigações internacionais.

Conforme Ramos (2002, p. 8-9), “a responsabilidade internacional do Estado é a reação jurídica do Direito Internacional às violações de suas normas, exigindo a preservação da ordem jurídica vigente".

Nesta esteira, Menezes (2009, p. 9) conceitua o controle de convencionalidade como o "mecanismo de responsabilização internacional do Estado por violação de direitos humanos".

Silva (2018, p. 46) ensina que o controle de constitucionalidade diz respeito ao estudo da (in)compatibilidade das leis com a Constituição, enquanto que o controle de convencionalidade compreende a verificação da (in)compatibilidade das leis com os 
tratados de direitos humanos (formalmente ou apenas materialmente constitucionais) que estão em vigência no país.

Assim, em paralelo ao bloco de constitucionalidade tratado no tópico anterior, o chamado "bloco de convencionalidade" contempla todos os tratados de direitos humanos dos quais o país é signatário, que constituem modelo para o controle de convencionalidade, não apenas a Convenção Americana de Direitos Humanos (SILVA, 2018, p. 75).

Além dos tratados internacionais de direitos humanos, a jurisprudência dos tribunais internacionais também integra o mencionado "bloco de convencionalidade", que, segundo Silva (2018, p. 76), "funciona como parâmetro e "referencial ético" aos magistrados e tribunais domésticos ao implementarem o controle de convencionalidade", ou seja, é base para a análise da compatibilidade de normas internas com as normas internacionais de proteção de direitos humanos.

O controle de convencionalidade insere-se justamente no contexto da obrigatoriedade dos Estados em assegurar a efetividade dos direitos humanos quando há a ratificação dos tratados internacionais, independentemente da atuação do Legislativo na adequação da ordem interna à ordem internacional. Esta é a lição de Trindade (2003, p. 517):

\footnotetext{
Os próprios tratados de direitos humanos atribuem uma função capital à proteção por parte dos tribunais internos, como evidenciado pelas obrigações de fornecer recursos internos eficazes e de esgotá-los, que recaem, respectivamente, sobre os Estados demandados e os indivíduos reclamantes. Tendo a si confiadas a proteção primária dos direitos humanos, os tribunais internos têm, em contrapartida, que reconhecer e interpretar as disposições pertinentes dos tratados de direitos humanos. Neste contexto insere-se o controle judicial de convencionalidade, decorrente do dever do Estado de prover a garantia judicial efetiva ao jurisdicionado, ainda que inoperante o Legislativo quanto ao seu dever de adotar as medidas legislativas necessárias de adequação da ordem interna à ordem internacional.
}

Nesta esteira, a Lei 13.123/2015 possui várias incompatibilidades com alguns tratados internacionais sobre direitos humanos que regulam a matéria. Tais questões colocam em risco a segurança alimentar, farmacológica, agrícola e genética do Brasil, e, quiçá, do planeta. (MIRANDA, 2016, p. 86).

Embora a Lei 13.123/15 preveja a consulta prévia para os casos de conhecimento tradicional identificado, cria isenções à consulta, além de não ter sido realizada consulta prévia durante o processo de elaboração da lei, colidindo com a Convenção $n^{\circ} 169$ da OIT 
e com a Convenção da Diversidade Biológica, que integram o bloco de convencionalidade.

Miranda (2016, p. 89), ensina que "apenas o fato do processo legislativo da Lei 13.123/15 não ter garantindo a consulta prévia às comunidades tradicionais já seria suficiente para declarar a inconvencionalidade do marco legal da biodiversidade".

Sobre o tema, Távora (2015, p. 45) aponta que houve apenas uma audiência pública realizada no Senado Federal onde foi dada oportunidade aos povos indígenas, comunidades tradicionais e agricultores tradicionais para opinar sobre a Lei 13.123/2015, o que não é suficiente para caracterizar a consulta prévia ampla e transparente prevista na Convenção 169 da OIT:

\begin{abstract}
Não identificamos, no histórico da tramitação das proposições que resultaram na Lei $\mathrm{n}^{\mathbf{0}} \mathbf{1 3 . 1 2 3}$, de 2015 , consultas nesse sentido ou manifestações que possam ser interpretadas como anuência dos povos indígenas ou do órgão indigenista federal ao conteúdo da proposição. As poucas oportunidades dadas aos povos indígenas, às comunidades tradicionais e aos agricultores tradicionais para opinar sobre o assunto, em apenas uma audiência pública no Senado Federal, não apenas é insuficiente para caracterizar uma consulta ampla e transparente, como seria desejável num contexto democrático. Essa falha pode expor a União a responsabilização em âmbito nacional e internacional por impor aos índios uma lei sem antes os ouvir devidamente, em afronta ao disposto nessa Convenção. (grifo nosso).
\end{abstract}

Duprat (2014, p. 64) esclarece que a consulta prévia, livre e informada deve fazer parte do processo legislativo, e, que, portanto, uma consulta, onde o texto legal se apresenta como já decidido, não enseja a consulta prévia e informada prevista nos tratados internacionais em questão, justamente por não haver possibilidade de revisão do projeto inicial ou até mesmo de sua não realização:

A consulta é prévia exatamente porque é de boa-fé e tendente a chegar a um acordo. Isso significa que, antes de iniciado o processo decisório, as partes se colocam em um diálogo que permita, por meio de revisão de suas posições iniciais, se chegar à melhor decisão. Desse modo, a consulta traz em si, ontologicamente, a possibilidade de revisão do projeto inicial ou mesmo de sua não realização. Aquilo que se apresenta como já decidido não enseja, logicamente, consulta, pela sua impossibilidade de gerar qualquer reflexo na decisão.

Além disso, ainda existem mais incompatibilidades entre esta lei, a Convenção 169 da OIT e a Convenção da Diversidade Biológica. Vejamos. 
A Lei $13.123 / 2015$ criou uma subdivisão entre conhecimento tradicional associado de origem identificável e não identificável, especificando regras diferenciadas de consentimento, o que é incompatível com o disposto na Convenção 169 da OIT e na Convenção da Diversidade Biológica:

\begin{abstract}
Art. $9^{\circ} \mathrm{O}$ acesso ao conhecimento tradicional associado de origem identificável está condicionado à obtenção do consentimento prévio informado.

$\S 2^{\circ} \mathrm{O}$ acesso a conhecimento tradicional associado de origem não identificável independe de consentimento prévio informado.

$\S 3^{\circ} \mathrm{O}$ acesso ao patrimônio genético de variedade tradicional local ou crioula ou à raça localmente adaptada ou crioula para atividades agrícolas compreende 0 acesso ao conhecimento tradicional associado não identificável que deu origem à variedade ou à raça e não depende do consentimento prévio da população indígena, da comunidade tradicional ou do agricultor tradicional que cria, desenvolve, detém ou conserva a variedade ou a raça.
\end{abstract}

Segundo o disposto na referida lei, haverá isenção da consulta prévia nos casos de acesso ao conhecimento tradicional associado de origem não identificável e nos casos de acesso ao patrimônio genético de variedade tradicional local ou crioula ou à raça localmente adaptada ou crioula para atividades agrícolas, o que, por si só, conflita com as disposições da Convenção 169 da OIT e da Convenção da Diversidade Biológica.

Ademais, outro ponto que merece destaque é a forma da comprovação do consentimento prévio e informado, conforme previsão no $\S 1^{\circ}$, do Art. $9^{\circ}$, da Lei 13.123/15:

\footnotetext{
Art. $9^{\circ} \mathrm{O}$ acesso ao conhecimento tradicional associado de origem identificável está condicionado à obtenção do consentimento prévio informado.

$\S 1^{\circ}$ A comprovação do consentimento prévio informado poderá ocorrer, a critério da população indígena, da comunidade tradicional ou do agricultor tradicional, pelos seguintes instrumentos, na forma do regulamento:

I - Assinatura de termo de consentimento prévio;

II - Registro audiovisual do consentimento;

III - Parecer do órgão oficial competente; ou

IV - Adesão na forma prevista em protocolo comunitário.
}

Conforme destaca Miranda (2016, p. 91), “o consentimento prévio não é apenas um papel assinado, mas um processo mais amplo e complexo no qual deve ser garantida a ampla participação das comunidades tradicionais a serem afetadas".

Ou seja, nos termos do art. $6^{\circ}$ da Convenção 169 da OIT, os Estados têm a obrigação de consultar os povos indígenas e comunidades tradicionais interessados diante de todas medidas administrativas ou legislativas capazes de afetá-los diretamente 
mediante a forma adequada e com os procedimentos apropriados, inclusive por meio de suas instituições representativas.

Não há como "catalogar" uma forma de realização da consulta prévia, principalmente, pois, diante do multiculturalismo, da diversidade cultural, cada povo indígena ou comunidade tradicional possui a sua forma de se expressar, suas crenças, seus valores, seus ritos.

Outrossim, o inciso III do $\S^{\circ}$ do art. $9^{\circ}$ da Lei $13.123 / 2015$, conforme destaca Miranda (2016, p. 92), fere "o direito de autodeterminação das comunidades tradicionais, também previsto na Convenção $\mathrm{n}^{\circ} 169$ da OIT e, de forma mais expressa nos Arts $3^{\circ}$ e $4^{\circ}$ da Declaração das Nações Unidas sobre os Direitos dos Povos Indígenas”.

As formas de comprovação da "consulta prévia” prevista nos incisos I, II e III do $\S 1^{\circ}$ do art. $9^{\circ}$ da Lei 13.123/2015, quais sejam, "um simples documento, um evento isolado, um vídeo fora de contexto ou o parecer de uma autoridade, não caracterizam o consentimento prévio e informado previstos na Convenção no 169 da OIT e na Convenção sobre Diversidade Biológica” (grifo nosso) (MIRANDA, 2016, p. 91).

Nesta mesma linha, Yamada e Oliveira (2013, p. 13), ensinam que:

\begin{abstract}
A consulta é um processo de diálogo, de conversas justas e de boa-fé que garante a participação dos povos diretamente afetados, respeitando suas particularidades culturais, seu jeito e seus planos de vida e de futuro. Não se trata de um evento isolado, mas sim de conhecer as razões de todos os envolvidos, para que os governos tomem decisões que considerem e respeitem a diversidade cultural. Nesse processo, cada um deve ceder um pouco, tentando chegar a um acordo, e não dizer simplesmente sim ou não.
\end{abstract}

Ademais, a apropriação indevida do conhecimento tradicional associado, sem consulta a povos e comunidades tradicionais, tem gerado uma nova forma de colonialismo, sendo a cultura e a biodiversidade o objeto da apropriação, conforme ensina Shiva (2001, p. 42):

Quinhentos anos depois de Colombo, uma versão secular do mesmo projeto de colonização está em andamento por meio das patentes e dos direitos de propriedade intelectual (DPI). A Bula Papal foi substituída pelo Acordo Geral sobre Tarifas e Comércio (General Agreementon Tariffsand Trade, GATT). O princípio da ocupação efetiva pelos príncipes cristãos foi substituído pela ocupação efetiva por empresas transnacionais, apoiadas pelos governantes contemporâneos. A vacância das terras foi substituída pela vacância de formas de vida e espécies, modificadas pelas novas biotecnologias. O dever de incorporar selvagens ao cristianismo foi substituído pelo dever de incorporar economias locais e nacionais ao mercado global, e incorporar os sistemas nãoocidentais de conhecimento ao reducionismo da ciência e da tecnologia mercantilizada do mundo ocidental. 
Com isso, é possível verificar que, em relação à consulta prévia, livre e informada, a Lei 13.123/2015 é incompatível com tratados internacionais de direitos humanos, especialmente a Convenção sobre Diversidade Biológica e a Convenção no 169 da OIT.

Neste mesmo sentido, ensina Miranda (2016, p. 94):

\begin{abstract}
No tocante à consulta prévia, livre e informada, fica claro as diversas incompatibilidades do marco legal da biodiversidade com vários tratados internacionais de direitos humanos. Entre estes, destacam-se, a Convenção sobre Diversidade Biológica e a Convenção $\mathrm{n}^{\circ} 169$ da OIT. Tais inconvencionalidades levam a inaplicabilidade da Lei 13.123/15, uma vez que estes tratados de direitos humanos têm caráter supralegal, não podendo a norma infraconstitucional prevalecer.
\end{abstract}

Com relação às consequências da incompatibilidade de uma norma infraconstitucional com tratados internacionais dos quais o Brasil é signatário, Silva (2018, p. 110) ensina que a "inconvencionalidade (ou anticonvencionalidade) provoca a invalidade causal da norma assim qualificada, pois carece, desde o início, de efeitos jurídicos".

Quanto a seus efeitos, o controle de convencionalidade possui efeitos inter partes $^{12}$, pela via difusa, uma vez que a norma impugnada não é aplicada no caso concreto, mas também não é derrogada. Por ser incompatível com direito superior (no presente caso, com a Convenção 169 da OIT e com a Convenção sobre a Diversidade Biológica) não há a efetivação da norma questionada (SILVA, 2018, p. 111).

Além disso, também pode ser realizado o controle de convencionalidade no sistema jurídico brasileiro, com efeito erga omnes (controle concentrado de convencionalidade) pelo Supremo Tribunal Federal e, em caráter complementar, pela Corte Interamericana de Direitos Humanos, caso o Poder Judiciário nacional não tenha implementado tal controle, ou tenha realizado de forma equivocada ou incompleta, conforme ensina Silva (2018, p. 112):

\begin{abstract}
Para o controle concentrado de convencionalidade no sistema jurídico brasileiro, também como já exposto, a verificação da inconvencionalidade da norma, com efeito erga omnes, será realizada pelo Supremo Tribunal Federal e em caráter complementar, também pela Corte Interamericana de Direitos Humanos, caso o Poder Judiciário nacional não tenha implementado tal controle, ou tenha realizado de forma equivocada ou ainda incompleta.
\end{abstract}

\footnotetext{
${ }^{12}$ Silva (2018, p. 117) destaca, ainda, que "magistrados e tribunais locais possuem o dever de controlar exofficio a convencionalidade das leis, declarando a invalidade das normas internas (menos benéficas) que contrariem os tratados de direitos humanos vigentes no país". (grifo nosso).
} 
Com isso, conclui-se que as inconvencionalidades expostas levam à inaplicabilidade da Lei 13.123/15, quer se entenda que os tratados de direitos humanos têm caráter constitucional ou até mesmo supralegal, não podendo a norma infraconstitucional prevalecer.

\section{CONSIDERAÇÕES FINAIS}

O problema que envolveu esta pesquisa foi a verificação da compatibilidade da Lei 13.123/2015 com os tratados internacionais sobre os direitos humanos que o Brasil é signatário relacionados à temática da proteção do conhecimento tradicional associado, dentre os quais destacamos a Convenção 169 da OIT e a Convenção da Diversidade Biológica, que tratam da consulta livre, prévia e informada e que são parâmetro para a realização do controle de convencionalidade, uma vez que integram o chamado "bloco de convencionalidade".

O objetivo de analisar qual a hierarquia jurídica dos tratados internacionais de direitos humanos no Brasil foi alcançado, uma vez que se expôs o posicionamento do Supremo Tribunal Federal, qual seja, o da supralegalidade dos tratados internacionais que não ingressaram no ordenamento jurídico pátrio conforme o rito do $\S 3^{\circ}$ do art. $5^{\circ}$ da Constituição, bem como foi estudado o pensamento de parte da doutrina que sustenta a posição hierárquica constitucional destes tratados, teoria defendida por este trabalho.

Ademais, foi analisado o instituto do controle de convencionalidade, destacando sua relevância para conferir efetividade aos tratados internacionais de direitos humanos e, assim, evitar violações de direitos no plano interno e retrocesso em matéria legislativa, realizando a comparação entre a Lei 13.123/2015 e a Convenção 169 da OIT e a Convenção da Diversidade Biológica, a fim de identificar a compatibilidade destas leis com as normas internacionais.

Com isso, é possível verificar em relação à consulta prévia, livre e informada, que a Lei 13.123/2015 é incompatível com a Convenção sobre Diversidade Biológica e a Convenção n 169 da OIT, primeiramente no que tange ao processo de elaboração da lei, pois não foi realizada a consulta prévia aos povos indígenas e comunidades tradicionais, situação em desacordo com o conteúdo expresso do art. $6^{\circ} 1$ da Convenção 169 da OIT.

Além disso, a Lei 13.123/2015 também criou uma distinção entre conhecimento tradicional associado identificável e não identificável, isentando o "não identificável” da realização da consulta prévia e trouxe uma nova forma da comprovação do consentimento 
prévio e informado, conforme previsão no seu $\$ 1^{\circ}$, art. $9^{\circ}$, que viola o disposto nos tratados internacionais de direitos humanos.

Outrossim, as formas de comprovação da consulta prévia prevista nos incisos I, II e III do $\S 1^{\circ}$ do art. $9^{\circ}$ da Lei 13.123/2015, quais sejam, a assinatura de um termo de consentimento prévio, um vídeo fora de contexto ou o parecer de uma autoridade, não caracterizam o consentimento prévio e informado previstos na Convenção $n^{\circ} 169$ da OIT e na Convenção sobre Diversidade Biológica, principalmente porque não dão margem para a manifestação de povos indígenas e comunidades tradicionais justamente por não haver possibilidade de revisão do projeto inicial da lei ou até mesmo de sua não realização.

Desta forma, conclui-se que as inconvencionalidades levam à inaplicabilidade da Lei 13.123/15, quer se entenda que os tratados de direitos humanos têm caráter constitucional ou até mesmo supralegal, não podendo a norma infraconstitucional que viola tratados internacionais de direitos humanos dos quais o Brasil é signatário prevalecer.

\section{REFERÊNCIAS}

ARAUJO JUNIOR, Júlio José. Direitos territoriais indígenas - uma interpretação intercultural. Rio de Janeiro: Processo, 2018.

AVELAR, Daniel; PRONER, Carol. A natureza jurídica dos tratados internacionais de direitos humanos e sua harmonização e aplicabilidade no ordenamento jurídico brasileiro. Revista de Direitos Fundamentais e Democracia, Curitiba, v. 10, n. 10, p. 3887, jul./dez. 2011.

BOBBIO, Norberto. Teoria do ordenamento jurídico. Tradução de Maria Celeste Cordeiro Leite dos Santos. 10.ed. Brasília: Editora Universidade de Brasília, 1999.

BRASIL, Decreto $n^{o} 2.519$, de 16 de março de 1998. Promulga a Convenção sobre Diversidade Biológica, assinada no Rio de Janeiro, em 05 de junho de 1992. Brasília, DF, 1998.

BRASIL. Constituição da República Federativa do. Congresso Nacional, Brasília, 1998.

BRASIL. Decreto n. 6.040, de 7 de fevereiro de 2007. Institui a Política Nacional de Desenvolvimento Sustentável dos Povos e Comunidades Tradicionais. Diário Oficial da União, Poder Executivo, Brasília, DF, 8 fev 2007.

BRASIL. Decreto $n^{o}$ 5.051, de 19 de abril de 2004. Promulga a Convenção no 169 da Organização Internacional do Trabalho - OIT sobre Povos Indígenas e Tribais. Brasília, DF, 2004. 
BRASIL. Lei Federal 6.938/81. Dispõe sobre a Política Nacional do Meio Ambiente, seus fins e mecanismos de formulação e aplicação, e dá outras providências. Congresso Nacional, Brasília, 1981.

BRASIL. Lei $n^{\circ} 13.123$, de 20 de maio de 2015. Regulamenta o inciso II do $\S 1^{\circ}$ e o $\S 4^{\circ}$ do art. 225 da Constituição Federal, o Artigo 1, a alínea j do Artigo 8, a alínea c do Artigo 10, o Artigo 15 e os $\S \S 3$ do Artigo 16 da Convenção sobre Diversidade Biológica, promulgada pelo Decreto $\mathrm{n}^{\circ} 2.519$, de 16 de março de 1998; dispõe sobre o acesso ao patrimônio genético, sobre a proteção e o acesso ao conhecimento tradicional associado e sobre a repartição de benefícios para conservação e uso sustentável da biodiversidade; revoga a Medida Provisória no 2.186-16, de 23 de agosto de 2001; e dá outras providências. Diário Oficial da União, Poder Executivo, Brasília, DF, 14 maio 2015.

BRASIL. Supremo Tribunal Federal. RE. 349703/RS. Rel. Min. Carlos Britto. Rel. Acordão Min. Gilmar Mendes. Tribunal Pleno, julgamento em 03/12/08, DJe-104 de 05/06/09.

CANOTILHO, José Joaquim Gomes. Direito constitucional e teoria da constituição. 7.ed. Coimbra: Almedina, 2003.

CORTE IDH. Caso Ximenes Lopes versus Brasil. Sentença de 4 de julho de 2006 Disponível em >http://www.corteidh.or.cr/docs/casos/articulos/seriec_149_por.pdf<, acesso em 19 de abril de 2019.

FAJARDO, Raquel. Aos 20 anos do Convênio 169 da OIT: Balanço e desafios da implementação dos direitos dos Povos Indígenas na América Latina. In: Povos Indígenas: Constituições e reformas Políticas na américa Latina / [organizador ricardoverdum]. Brasília: Instituto de Estudos socioeconômicos, 2009.

FELICIANO, Guilherme. A prisão civil do depositário judicial infiel economicamente incapaz: um outro olhar. In: Revista do Tribunal Regional do Trabalho da $15^{\text {a }}$ Região / Tribunal Regional do Trabalho da $15^{\mathrm{a}}$ Região, Escola Judicial do TRT - $15^{\mathrm{a}}$ Região Campinas/SP, n. 35, jul./ dez. 2009

LOUREIRO, Sílvia Maria da Silveira. A Proteção Constitucional dos Direitos Humanos: "é preciso imaginar Sísifo feliz." In: Revista Via Legis, 2007, ns. 55/56.

LOUREIRO, Silvia Maria da Silveira. Tratados Internacionais sobre Direitos Humanos na Constituição. Belo Horizonte: Del Rey, 2005.

MAZZUOLI, Valério de Oliveira. A incorporação dos tratados internacionais de proteção dos direitos humanos no ordenamento brasileiro. Revista de Informação Legislativa. Brasília, a. 37, n. 147, jul./set. 2000.

MAZZUOLI, Valério de Oliveira. Hierarquia constituição e incorporação automática dos tratados de proteção dos direitos humanos no direito brasileiro. Revista de Informação Legislativa. Brasília a. 37 n. 148 out./dez. 2000.

MAZZUOLI, Valerio de Oliveira. O novo $\S 3^{\circ}$ do art. $5^{\circ}$ da constituição e sua eficácia. Revista de Informação Legislativa, Brasília, a. 42, n. 167, jul./set. 2005. 
MENEZES, André Felipe Barbosa de. Controle de convencionalidade no sistema interamericano de direitos humanos. 2009. 361 f. Tese (Doutorado em Direito Universidade Federal de Pernambuco, Recife, 2009. Disponível em: <http://www.bdtd.ufpe.br/tedeSimplificado//tde_busca/arquivo.php?codArquivo=6937> . Acesso em 17 de abril de 2019.

MIRANDA, João Paulo de Rocha. O Marco Legal da Biodiversidade e o Controle de Convencionalidade. In: Direito ambiental e socioambientalismo III [Recurso eletrônico on-line] organização CONPEDI/UnB/UCB/IDP/UDF; Coordenadores: José Fernando Vidal De Souza, Leonardo Estrela Borges, Norma Sueli Padilha - Florianópolis: CONPEDI, 2016.

MMA. Ministério do Meio Ambiente. Convenção sobre diversidade biológica. Brasília: MMA, 2000. p.15-16.

MOREIRA, Eliane Cristina Pinto. O direito dos povos tradicionais sobre seus conhecimentos associados à biodiversidade: as distintas dimensões destes direitos e seus cenários de disputa. In: BARROS, Benedita da Silva; ARCÉS, Claudia Leonor López; MOREIRA, Eliane Cristina Pinto; PINHEIRO, Antônio do Socorro Ferreira (org.). Proteção aos Conhecimentos das Sociedades Tradicionais. Belém: Museu Paraense Emílio Goeldi: Centro Universitário do Pará, 2006. p:309332.

OIT. Convenção n ${ }^{\circ} 169$ sobre povos indígenas e tribais e Resolução referente à ação da OIT. Brasília-DF: OIT, 2011.

OLIVEIRA, Jesus Vieira de.A Proibição de retrocesso e a isenção de repartição de benefícios ao ramo empresarial para fins de acesso a conhecimento tradicional. Dissertação de Mestrado - Instituto de Ciências Jurídicas, Programa de Pós-Graduação em Direito, Mestrado Interinstitucional UFPA/UFMT/UNEMA, Universidade Federal do Pará, 2016.

DUPRAT, Deborah. Pareceres Jurídicos: Direitos dos Povos e Comunidades Tradicionais, EU, Manaus, 2007.

DUPRAT, Deborah. A Convenção 169 da OIT e o direito à consulta prévia, livre e informada. Revista Culturas Jurídicas. Revista do programa de pós-graduação em Direito Constitucional da UFF. Niteroi, RJ, Vol. 1, n 1, p.51-72, 2014.

PIOVESAN, Flávia. A Constituição Brasileira de 1988 e os tratados internacionais de proteção dos direitos humanos. In: a Proteção Internacional dos Direitos Humanos e o Brasil. Superior Tribunal de Justiça, Brasília, 2000. Disponível em: <https://ww2.stj.jus.br/publicacaoinstitucional/index.php/API/issue/view/378/showToc $>$, Acesso em: 17 de abril de 2019.

RAMOS, André de Carvalho. O impacto da Convenção Americana de Direitos Humanos na relação do direito internacional e o direito interno. Boletim Científico da Escola Superior do Ministério Público da União, Brasília, ano 1, n. 4, p. 51-71, jul/set. 2002

RAMOS, André de Carvalho.Tratados internacionais: novos espaços de atuação do Ministério Público. Boletim Científico da Escola Superior do Ministério Público da União, Brasília, ano 2, n. 7, p. 81-100, abr./jun. 2003.

SAGÜES, Nestor Pedro. Obligacionesinternacionales y control de convencionalidad. EstudiosConstitucionales, ano 8, n. 1, p. 117-136, 2010. Disponível em: 
<http://www.cecoch.cl/docs/pdf/revista_ano8_1_2010/articulo_4.pdf >. Acesso em: 17 de abril de 2019.

SHIVA, Vandana. Biopirataria: a pilhagem da natureza e do conhecimento. Tradução de Laura Cardellini Barbosa de Oliveira. Petrópolis, RJ: Vozes, 2001. p.42.

SILVA, Geraldo Eulálio do Nascimento e. Direito ambiental internacional. 2 ed, rev, atual, Rio de Janeiro: Thex, 2002. p. 130-131.

SILVEIRA LOUREIRO, Silvia Maria da; BRITO SILVA, JamillyIzabela de. O modelo janicéfalo de incorporação dos Tratados Internacionais Sobre Direitos Humanos Na Constituição: as perplexidades da validade e da aplicabilidade do novo parágrafo 3 o do artigo 5o. Revista do Instituto Brasileiro de Direitos Humanos, [S.1.], n. 9, p. 193-208, dez. 2009. ISSN 1677-1419. Disponível em: <http://revista.ibdh.org.br/index.php/ibdh/article/view/147>. Acesso em: 17 abr. 2019.

TÁVOORA, F. L. et al. Comentários à Lei $n^{o} 13.123$, de 20 de maio de 2015: Novo Marco Regulatório do Uso da Biodiversidade. Brasília: Núcleo de Estudos e Pesquisas/CONLEG/Senado, outubro/2015 (Texto para Discussão no 184). Disponível em: www.senado.leg.br/estudos. Acesso em 19 de maio de 2016.

TRINDADE, Antônio Augusto Cançado. A proteção internacional dos Direitos Humanos: Fundamentos e Instrumentos Básicos. São Paulo: Saraiva, 1991.

TRINDADE, Antônio Augusto Cançado. Tratado de Direito Internacional dos Direitos Humanos. v.1. 2. ed. ver. e atual. Porto Alegre: Sergio Antonio Fabris, 2003.

SILVA, Túlio Macedo Rosa e. Liberdade sindical e controle de convencionalidade. Tese de Doutorado - Faculdade de Direito, Universidade de São Paulo, São Paulo, 2018.

YAMADA, Erika M.; OLIVEIRA, Lucia Alberta Andrade (Orgs.). A Convenção 169 da OIT e o direito à consulta livre, prévia e informada. Brasília: Funai: GIZ, 2013. 